\title{
Modulation of Anxiolytic-Like and Antidepressant-Like Effects of Melatonin by Imipramine in Wistar Rats: Possible Interaction with Central Monoaminergic Systems
}

\author{
Sihame Ouakki, Oussama Zghari $₫$, Aboubaker El Hessni, Abdelhalem Mesfioui, Ali Ouichou \\ Unit of Nervous and Endocrine Physiology, Laboratory of Genetics, Neuroendocrinology and Biotechnology, University Ibn Tofail, \\ Kenitra, Morocco \\ Email: zghari.oussama.91@gmail.com
}

How to cite this paper: Ouakki, S., Zghari, O., El Hessni, A., Mesfioui, A. and Ouichou, A. (2019) Modulation of Anxiolytic-Like and Antidepressant-Like Effects of Melatonin by Imipramine in Wistar Rats: Possible Interaction with Central Monoaminergic Systems. Neuroscience \& Medicine, 10, 118-133.

https://doi.org/10.4236/nm.2019.102008

Received: February 23, 2019

Accepted: June 1, 2019

Published: June 4, 2019

Copyright $\odot 2019$ by author(s) and Scientific Research Publishing Inc. This work is licensed under the Creative Commons Attribution International License (CC BY 4.0).

http://creativecommons.org/licenses/by/4.0/

(c) (i) Open Access

\begin{abstract}
Our current study aims to explore the interaction of melatonin (MEL) with the monoaminergic system on the pathophysiology of affective disorders in Wistar rats. We mention here that, the role of monoaminergic transmission in the pathophysiology of affective disorders in humans is demonstrated in most recent reports. In this sense, our current work aims to explore the effect of melatonin (MEL) with or without imipramine (IMP) on levels of depression and anxiety in Wistar rats and would determine the role of MEL in modulating serotonin, noradrenaline and dopamine neurotransmission. From this point, twenty-four female Wister rats were divided into 4 groups of 6 animals and received subcutaneously during 4 weeks different doses of MEL $(4 \mathrm{mg} / \mathrm{kg})$, IMP ( $2 \mathrm{mg} / \mathrm{kg})$ or MEL $(4 \mathrm{mg} / \mathrm{kg})+$ IMP $(2 \mathrm{mg} / \mathrm{kg})$. Behavioral performance especially anxiety and depression is measured in the open field (OFT), elevated plus maze (EPM) and forced swim test (FST). The anxiety-like and antidepressant-like effects were observed with MEL at $4 \mathrm{mg} / \mathrm{Kg}$ and IMP at 2 $\mathrm{mg} / \mathrm{Kg}$ but the potentiating effect was more observed with the two combined molecules (MEL and IMP), since locomotors activity assessed by the OFT and EPM was not affected. These effects suggest that psychopharmacological actions of MEL are due, at least in part, to its ability to potentiate the central monoaminergic transmitter effects.
\end{abstract}

\section{Keywords}

Melatonin, Imipramine, Depression, Anxiety, Open Field Test, Elevated Plus Maze, Forced Swimming Test 


\section{Introduction}

There is a clear relationship between the affective disorders and brain levels of monoaminergic neurotransmitters serotonin (5-HT), noradrenalin (NA) and dopamine (DA). Depression is characterized by a decrease in 5-HT levels in the brain, particularly in the various structures of the limbic system. 5-HT-ergic system is also involved in the control of anxiety, and almost certainly, in the pathogenesis of all anxiety disorders. The fact that some antidepressants that increase brain neurotransmitter 5-HT-ergic relieve anxiety symptoms suggests that anxiety disorders share common mechanisms etiopathological with depression [1].

The treatment of affective disorders by antidepressants, especially tricyclic antidepressants (TCA) is effected by activation of 5HT-ergic, by inhibiting the reuptake of 5-HT, inhibiting its degradation by $\mathrm{MAO}$, or indirectly by blocking the 22 -receptors NA-ergiques [2]. Among these antidepressants, IMP is known to block neuronal reuptake of NA and 5-HT. Its action extends to other neurotransmitters by inhibiting the reuptake of DA, cholinergic muscarinic receptors, histamine $\mathrm{H} 1$ receptors and $\alpha 1$-NA-ergic receptors.

Furthermore, the MEL is a hormone produced primarily by the pineal gland from its precursor, L-tryptophan (L-TRP) under the action of various enzymes. The first step is the absorption of L-TRP by pinealocytes before its conversion into 5-Hydroxytryptophan (5-HTP) by the TRP-hydroxylase. Decarboxylation of 5-HTP by L-aromatic decarboxylase leads to the formation of 5-HT. The acetylation of 5-HT by $\mathrm{N}$-acetyltransferase (NAT) leads to the formation of the $\mathrm{N}$-acétylsérotonine (NAS). Finally, methylation of the NAS by hydroxyindole-O-methyltransferase (HIOMT) results in the synthesis of the final product, the MEL. In all mammals, MEL is synthesized and released according to a circadian rhythm, the peak of hormonal secretion always coincide with night time; the maximum production of the hormone occurring around 3 am or 4 am. MEL released by pinealocytes into the general circulation binds to plasma proteins to reach various central and peripheral targets. At these levels, the MEL binds to its receptors and specific binding sites to induce a variety of physiological and behavioral functions.

Behaviorally, the relationship between anxiety and depressive disorders and MEL has been reported in many studies in various species including humans. Significant changes in the rhythmic secretion of MEL have been detected in patients with affective disorders. It has been also shown a correlation between low levels of nocturnal MEL in subjects with major depression or panic disorder [3]. This was also observed in subjects with melancholic depression. In contrast, higher levels of MEL than normal were observed in some patients during the manic phase [4]. The amplitude of the circadian rhythm of MEL who is blunted in patients with depression, is more important than changes in the level of absolute MEL. However, other studies have not permit to show a change in the MEL secretion profile in depressed patients; circulating levels of the hormone nor- 
mally tend to rise during the night. Other alterations in the endogenous rhythm MEL were also reported in some depressed patients, with a phase advance.

Animal studies based on exogenous hormone intake have shown the involvement of MEL in the modulation of affective disorders. Thus, chronic administration of MEL showed anxiolytic effects and/or antidepressant in many models of anxiety and depression [5]. In rodents, except the study of Wong and Ong (2001) [6], who reported sedative but not anxiolytic effect of MEL in rats, all works using animal models of anxiety, such as the passive avoidance test, open field test, light/dark box and elevated plus maze are consistent on the anti-anxiety character of the pineal hormone [7]. With respect to depression, studies show that the MEL exerts antidepressant action in the tail suspension test and forced swimming test (FST), which are considered predictive tests of the effectiveness of antidepressants in humans.

The interaction of MEL with aminergic systems in the regulation of affective disorders has been suggested by some studies. In rats and mice, MEL associated with reserpine, alkaloid antidepressant known to bind to the neurotransmitter storage vesicles, such as NA, 5-HT and DA, reduces the level of depression [8].

In view of these data, the ability to increase antidepressant and anxiolytic effects of conventional drugs by MEL pretreatment may be a favorable option for patients resistant to drugs. Based on this concept, the aim of this study was to explore the putative synergistic effect of the IMP [9] and MEL on anxiety levels in the OFT and the EPM and on depression levels in the FST in Wistar rats. This study can be interesting because it will show a possible interaction of the pineal hormone with the aminergic system and therefore help to understand MEL action mechanisms. For this purpose, we undertake to explore the effect of 2 $\mathrm{mg} / \mathrm{kg}$ of IMP alone or in combination with $4 \mathrm{mg} / \mathrm{Kg}$ of MEL on anxiety-like and depression-like levels in Wistar rats.

\section{Material and Methods}

\subsection{Animals and Pharmacological Treatments}

This experiment was used to study the effects of the pineal hormone in combination with IMP on female Wistar rats (from University Ibn Tofail) aged 8 to 9 weeks, initially weighing $120 \pm 20 \mathrm{~g}$ and were grouped by six in cages (LWH: $36 / 20 / 15 \mathrm{~cm}$ ). Rats were maintained under LD $12 / 12$ and at a standard temperature of $21^{\circ} \mathrm{C} \pm 1^{\circ} \mathrm{C}$. Water and food were provided ad libitum. At the beginning of experiments, the colony room was maintained under a long photoperiod LD: 16/8 (16 h Light/8h Darkness). All experimental procedures were approved by the University Ethics Committee for Animal Experiments.

Animals were divided into 4 groups of 6 animals as following:

- Group 1 (control): rats injected with saline solution $\mathrm{NaCl}(0.9 \%)$ as vehicle containing $5 \%$ ethanol,

- Group 2 (MEL-4): rats injected with $4 \mathrm{mg} / \mathrm{Kg}$ of MEL,

- Group 3 (IMP-2): rats injected with $2 \mathrm{mg} / \mathrm{Kg}$ of IMP, 
- Group 4 (MEL-4 + IMP-2): rats injected simultaneously with $4 \mathrm{mg} / \mathrm{kg}$ MEL and $2 \mathrm{mg} / \mathrm{Kg}$ IMP.

Saline solution $\mathrm{NaCl}$ (0.9\%) containing 5\% ethanol, MEL (obtained from Sigma: France Lot. 112K0998) or IMP (obtained from Pharma Laboratories (Morocco)) were injected subcutaneously, once daily, at the rate approximately at 4:00 pm $(2 \mathrm{~h}$ before dark phase) during 4 weeks. To consider body weight evolution, injected volumes are adjusted twice a week on body growth of animals.

\subsection{Anxiety-Like Measurement}

\section{Open Field Test:}

The OFT used in this study is conform to that previously reported [10]. The maze adopted is made of wood $(100 \mathrm{~cm} \times 100 \mathrm{~cm})$ enclosed with $40 \mathrm{~cm}$ high walls and placed under strong illumination (100 W, $2 \mathrm{~m}$ above the apparatus). The area was divided into 25 squares $(20 \mathrm{~cm} \times 20 \mathrm{~cm})$, defined as 9 central and 16 peripheral squares. At the beginning of the $10 \mathrm{~min}$ test, the animal was placed in the centre of the apparatus and its behavior was videotaped for subsequent analysis. The quantified parameters were the time spent in the center of the area (TCA) and the number of returns to the center (NRC). Central perimeter residence time is used as a measure of anxiety. The number of returns to the central area is also an indicator of the emotional reactivity. The central area of a novel environment is anxiogenic and aversive and the behavioral inhibition appears therefore as an avoidance behavior towards the central zone of the OFT. Number of total squares (NTS) represents Locomotors activity. The apparatus was cleaned between each examination using $70 \%$ ethyl alcohol.

\section{Elevated Plus-Maze Test:}

The EPM is an ethological model of anxiety in rodents provoked by the novelty and repulsion as a result of elevation and illumination of the maze [11]. This test is based on the creation of a conflict between the exploratory drive of the rat and its innate fear of open and exposed areas; it has been validated for the detection of emotional responses to anxiogenic and anxiolytic substances. Thus, increased open-arms exploration indicates reduced anxiety-related behavior. The EPM consists of a wooden plus-shaped platform elevated $70 \mathrm{~cm}$ above the floor. Two of the opposing arms $(50 \mathrm{~cm} \times 10 \mathrm{~cm})$ are closed by $40 \mathrm{~cm}$ high side and end walls, having an open roof. In order to avoid fall, the other two arms (open arms) were surrounded by $0.5 \mathrm{~cm}$ high edge, the four arms had at their intersection a central platform $(10 \mathrm{~cm} \times 10 \mathrm{~cm})$. A 100 -W lamp was placed exactly over the central platform. At the beginning of the test, the rats were placed on the central area of the maze facing an open arm. The following parameters of anxiety-related behavior were measured during the 5 min testing period: 1) entries into open arms (EOA), 2) time spent on the open arms (TOA), and 3) number of full entries into the arms (TAE). Decreased anxiety-like behavior is illustrated by a significant statistical increase of parameters in open arms (time and/or entries). The total number of the entries into all arms provides general 
hyperactivity. To eliminate any lingering olfactory cues, the apparatus was cleaned between each examination using $70 \%$ ethyl alcohol.

\subsection{Depression-Like Measurement}

The FST is an excellent maze used to assess the depressive-like behavior [12]. Swimming sessions were conducted by placing the rat in individual glass cylinders (height $=50 \mathrm{~cm}$; diameter $=30 \mathrm{~cm})$ containing $30 \mathrm{~cm}$ of water at $\left(23^{\circ} \mathrm{C} \pm\right.$ $2^{\circ} \mathrm{C}$ ). During the session, rats were forced to swim for $5 \mathrm{~min}$ and the duration of immobility was measured. The latency to the first bout of immobility was also recorded starting immediately after placing the rats in the cylinder. A rat was considered immobile when it ceased all active behaviors (i.e. struggling, swimming and jumping) and remained passively floating or making minimal movements necessary to maintain the nostrils above water. High percent time floating is interpreted as an increased depressive-like response.

\subsection{Quantitative Presentation of the Results and Statistics}

The importance of behavioral responses of different experimental groups is determined by considering the control group in each experiment as the basal level (BL) number equal to $100 \%$. The effects of different treatments were then calculated relative to this baseline. All data are expressed as the means \pm standard error of the means (S.E.M.). To determine the differences between experimental groups statistical analysis was performed by analysis of variance (ANOVA) $1^{\text {st }} / 2^{\text {nd }}$ order followed by a post-hoc tests (Fisher LSD) or Student test "t". Differences were considered significant when $\mathrm{p}<0.05$, very significant when $\mathrm{p}<$ 0.01 and highly significant when $\mathrm{p}<0.001$.

\section{Result}

\subsection{Effect of MEL and/or IMP on Anxiety Level in Open Field Test}

- Time spent in the central area (TCA) (Figure 1(a)):

The results summarized in Figure 1(a) show that MEL at $4 \mathrm{mg} / \mathrm{kg}$, IMP at 2 $\mathrm{mg} / \mathrm{kg}$ and two associated molecules stimulate TCA in comparison with the control group [(control/MEL-4: $\mathrm{p}<0.05)$; (control/IMP-2: $\mathrm{p}<0.05$ ); (control/MEL-4 + IMP-2: $\mathrm{p}<0.01)]$. Similar results were obtained by considering the relative comparison (TCA\% BL) between treated and control groups. MEL, IMP and 2 associated molecules MEL + IMP induced respectively an average increase of 34\% ( $\mathrm{p}<0.05) ; 27 \%(\mathrm{p}<0.05) ; 45 \%(\mathrm{p}<0.01)$. However, no significant difference was found between different drug treated groups [(MEL-4/IMP-2: $\mathrm{p}>$ 0.05); (MEL-4/MEL-4 + IMP-2: p > 0.05); (IMP-2/MEL-4 + IMP-2: p > 0.05)].

- Number of returns to the center (NRC) (Figure 1(b)):

As for TCA, NRC parameter is also increased by the MEL, IMP and two associated molecules with comparison to the control group [(control/MEL-4: $\mathrm{p}<$ 0.001); (control/IMP-2: $\mathrm{p}<0.001$ ); (control/MEL-4 + IMP-2: $\mathrm{p}<0.001)$ ]. Similar results were obtained by referring to relative comparison (NRC\% BL) between 


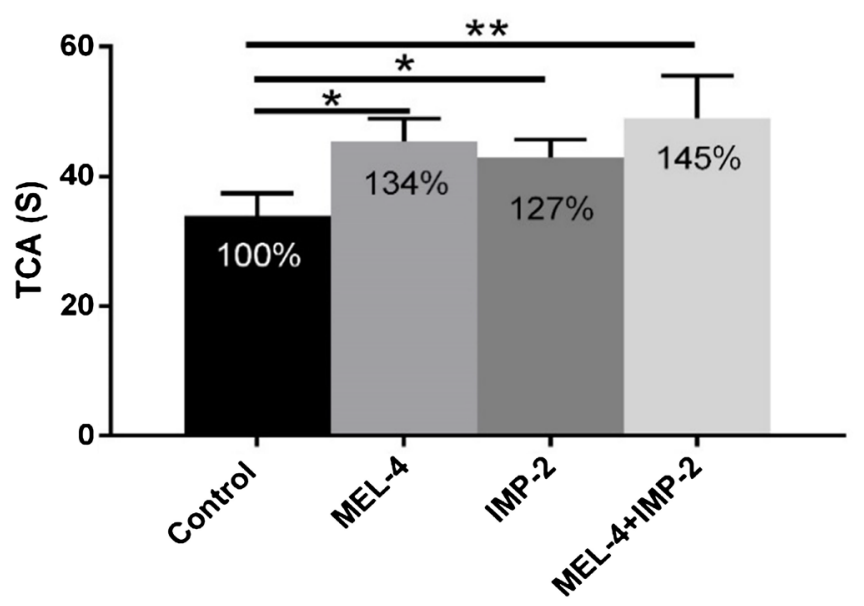

(a)

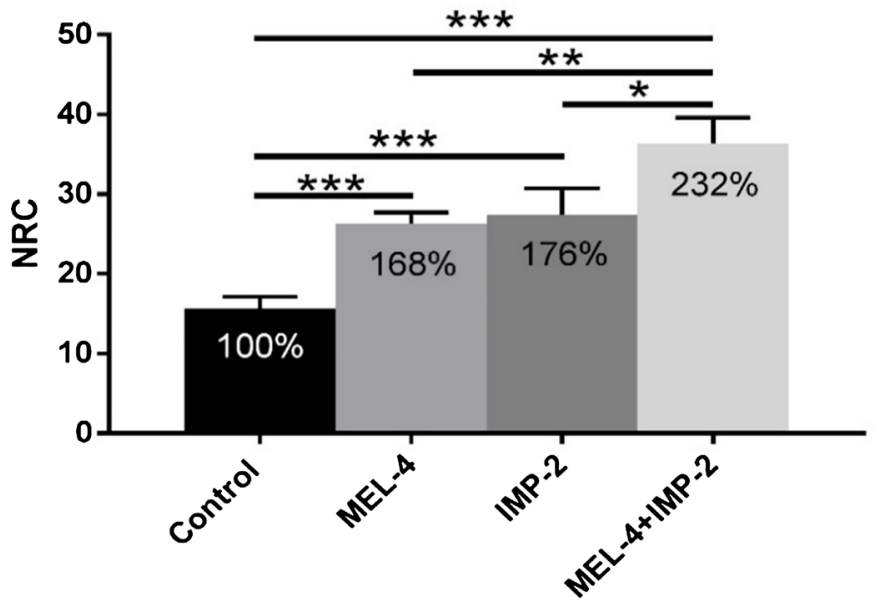

(b)

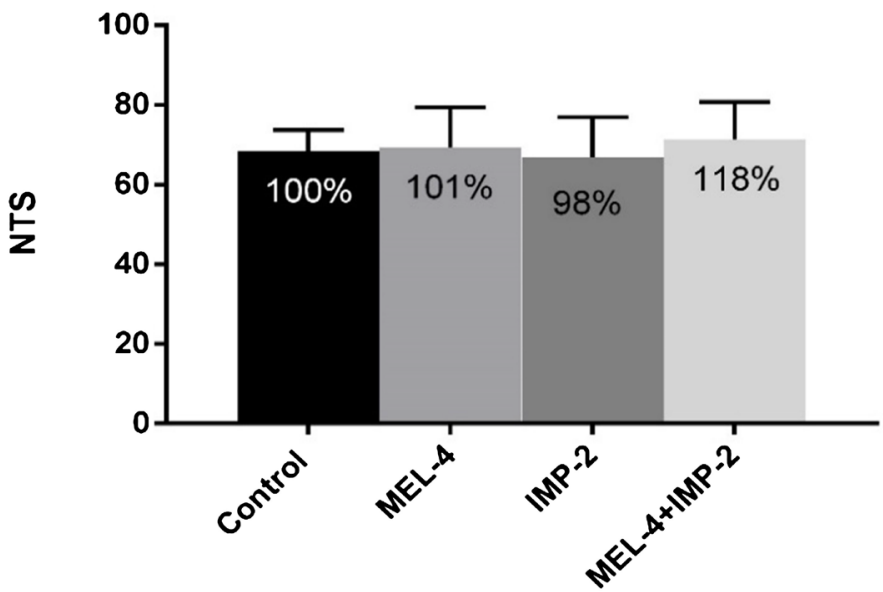

(c)

Figure 1. (a) Total amount time spent in the center (TCA); (b) Number of return into center (NRC); and (c) Number of total squares (NTS) in the OFT by rats expressed as arbitrary values or as \% of basal level (\% BL), after 4 weeks of treatment with $0.9 \%$ of $\mathrm{NaCl}$ (Control), $4 \mathrm{mg} / \mathrm{kg}$ of MEL (MEL-4), $2 \mathrm{mg} / \mathrm{kg}$ of IMP (IMP-2) or simultaneously with 4 $\mathrm{mg} / \mathrm{kg}$ of MEL and $2 \mathrm{mg} / \mathrm{kg}$ of IMP (MEL- $4+\mathrm{IMP}-2)$. The results are represented as mean \pm SEM. The significance level is $0.05 .{ }^{*} \mathrm{p}<0.05,{ }^{* *} \mathrm{p}<0.01,{ }^{* *} \mathrm{p}<0.001$. 
all treated and control groups. MEL, IMP and combined molecules produced an average enhancement of $68 \%, 76 \%$ and $132 \%$ respectively. These augmentations are higher than those observed with TCA of the same groups. In addition, the effect induced by two combined molecules (MEL + IMP) was statistically higher when compared to those of MEL (MEL-4/MEL-4 + IMP-2: $\mathrm{p}<0.01$ ) and of IMP (IMP-2/MEL-4 + IMP-2: $\mathrm{p}<0.05)$ treated groups. However, no significant difference was observed between MEL and IMP treated groups (MEL-4/IMP-2: $\mathrm{p}>0.05$ ).

- Number of total squares (NTS) (Figure 1(c)):

MEL, IMP or 2 combined associated did not alter significantly NTS parameter [(control/MEL-4: p > 0.05); (control/IMP-2: p > 0.05) and (control/MEL-4 + IMP-2: $\mathrm{p}>0.05)$ ]. Similar results were obtained by referring to relative comparison (NTS\% BL) between all treated and control groups. In addition, no significant difference was observed between the different drug treatments [(MEL-4/IMP-2: $\mathrm{p}>0.05$ ); (MEL-4/MEL-4 + IMP-2: $\mathrm{p}>0.05$ ); (IMP-2/MEL-4 + IMP-2: $\mathrm{p}>0.05)$ ].

\subsection{Effect of MEL and/or IMP on Anxiety Level in Elevated Plus Maze Test}

- Time spent in open arms (TOA) (Figure 2(a)):

MEL, IMP and the 2 associated molecules stimulated TOA in comparison with the control group [(control/MEL-4: $\mathrm{p}<0.05)$; (control/IMP-2: $\mathrm{p}<0.05$ ); (control/MEL-4 + IMP-2: $\mathrm{p}<0.01$ )]. Comparable data were reported with reference to the relative comparison (TOA\% NB) between treated and control groups. Indeed, MEL, IMP and 2 co-administrated substances produced respectively an average enhancement of 20\% (control/MEL-4: p $<0.05$ ), 25\% (control/IMP-2: $\mathrm{p}<0.05$ ) and of 48\% (control/MEL-4 + IMP-2: $\mathrm{p}<0.01$ ).

In addition, the simultaneous action of IMP and MEL on this parameter is statistically superior when compared to that of MEL (MEL-4/MEL-4 + IMP-2: $\mathrm{p}$ $<0.05)$. However, no significant difference was observed between the IMP and MEL or of combined two molecules [(MEL-4/IMP-2: $\mathrm{p}>0.05$ ); (IMP-2/MEL-4 + IMP-2: $\mathrm{p}>0.05$ )].

- Entries to open arms (EOA) (Figure 2(b)):

All treatments, MEL, IMP and IMP+MEL induced a significant increase of EOA in comparison to the control group [(control/MEL-4: $\mathrm{p}<0.05)$; (control/IMP-2: $\mathrm{p}<$ 0.05); (control/MEL-4 + IMP-2: $\mathrm{p}<0.001$ )]. Comparable data were reported with reference to the relative comparison (EOA \%NB) between control and all treated groups. MEL, IMP and combined molecules produced respectively an average elevation of $41 \%$ (control/MEL-4: $\mathrm{p}<0.05)$ ), $101 \%$ (control/IMP-2: $\mathrm{p}<0.05$ ) and of 115\% (control/MEL-4 + IMP-2: $\mathrm{p}<0.01$ ).

In contrast, no significant difference was noted between MEL-4/IMP-2 ( $\mathrm{p}>$ $0.05)$, MEL-4/MEL4 + IMP-2 ( $p>0.05)$ or IMP-2/MEL4 + IMP-2 ( $p>0.05)$ groups.

- Total entries in arms (TEA) (Figure 2(c)):

Neither MEL nor IMP or two associated molecules induced a significant effect on the TEA parameter [(control/MEL-4: $\mathrm{p}>0.05)$; (control/IMP-2: $\mathrm{p}>0.05)$ 


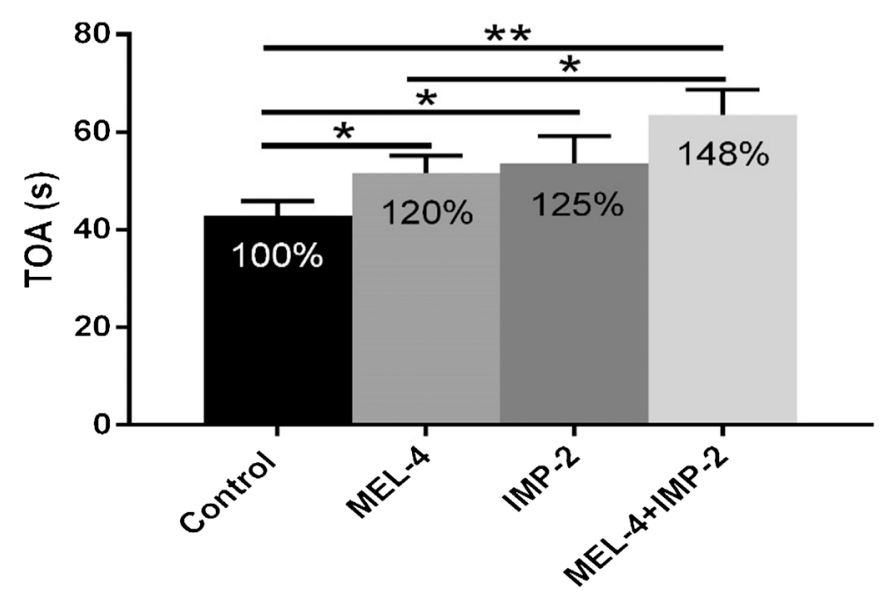

(a)

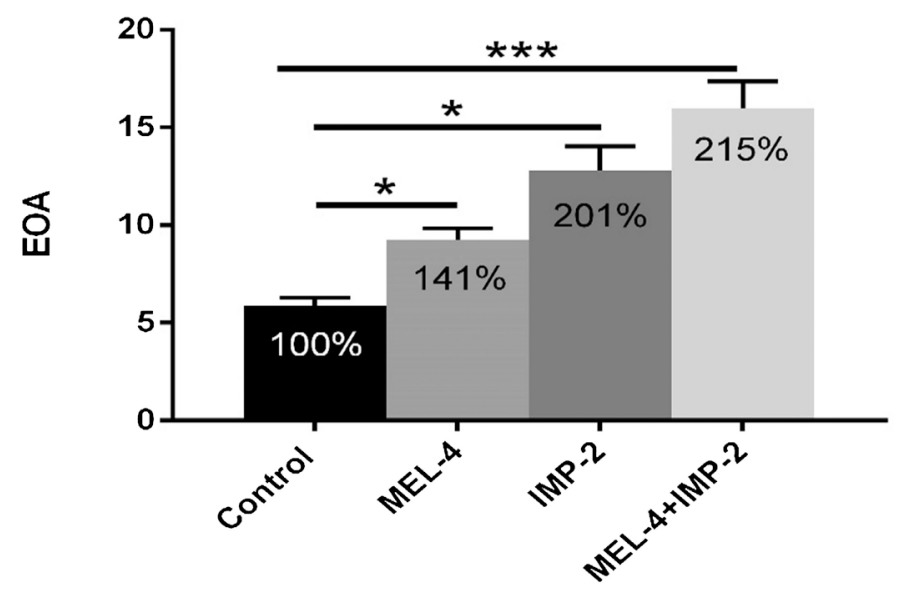

(b)

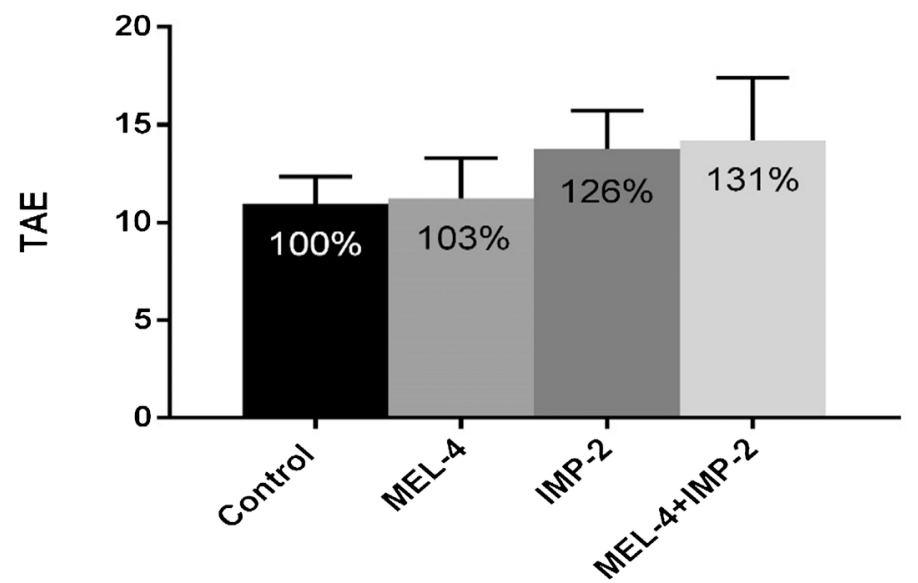

(c)

Figure 2. (a) Number of entries in exposed arms (EOA); (b) Total amount of time spent in exposed arms (TOA) and (c) Total number of arms entries (TEA) in EPM by rats expressed as arbitrary values or as \% of basal level (\% BL), after 4 weeks of treatment with $0.9 \%$ of $\mathrm{NaCl}$ (Control), $4 \mathrm{mg} / \mathrm{kg}$ of MEL (MEL-4), $2 \mathrm{mg} / \mathrm{kg}$ of IMP (IMP-2) or simultaneously with $4 \mathrm{mg} / \mathrm{kg}$ of MEL and $2 \mathrm{mg} / \mathrm{kg}$ of IMP (MEL- $4+$ IMP-2). The results are represented as mean $\pm \mathrm{SEM}$. The significance level is $0.05 .{ }^{*} \mathrm{p}<0.05,{ }^{* *} \mathrm{p}<0.01,{ }^{* *} \mathrm{p}<$ 0.001 . 
and (control/MEL-4 + IMP-2: p > 0.05)]. Also, no significant difference was observed between the different drug treatments [(MEL-4/IMP-2: $\mathrm{p}>0.05)$; (MEL-4/MEL-4 + IMP-2: p > 0.05); (IMP-2/MEL-4 + IMP-2: p > 0.05)]. Similar results were obtained by referring to relative comparison (TEA\% NB) between all treated and control groups.

\subsection{Effect of MEL and/or IMP on Depression-Like Level in Forced Swimming Test}

\section{- Effect on immobility time (TIM) (Figure 3(a)):}

In the FST, MEL, IMP and combined molecules strongly and significantly reduce the TIM [(control/MEL-4: $\mathrm{p}<0.01$ ); (control/IMP-2: $\mathrm{p}<0.001$ ); (control/MEL-4 + IMP-2: p < 0.001)]. MEL, IMP and (ML + IMP) induced a mean reduction of TIM of $31 \%(\mathrm{p}<0.01), 44 \%(\mathrm{p}<0.001)$ and $54 \%(\mathrm{p}<0.001)$ respectively.

The TIM of groups treated with IMP or simultaneously with MEL and IMP were

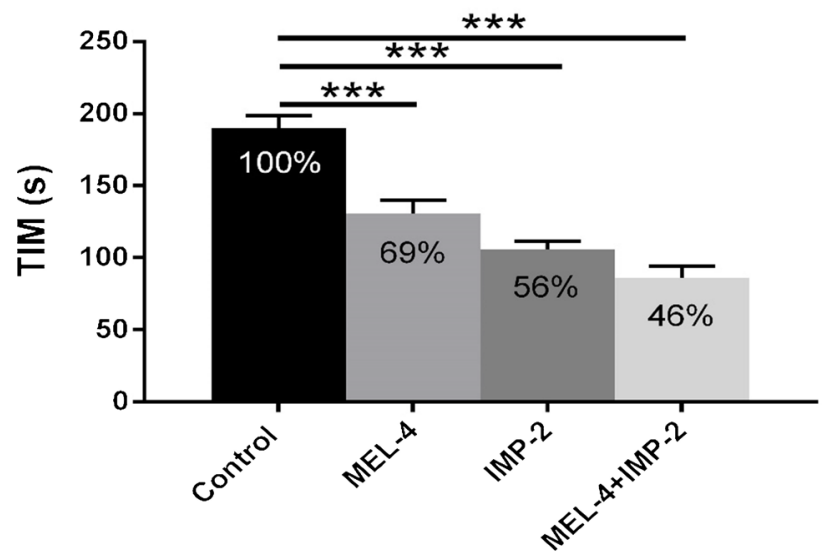

(a)

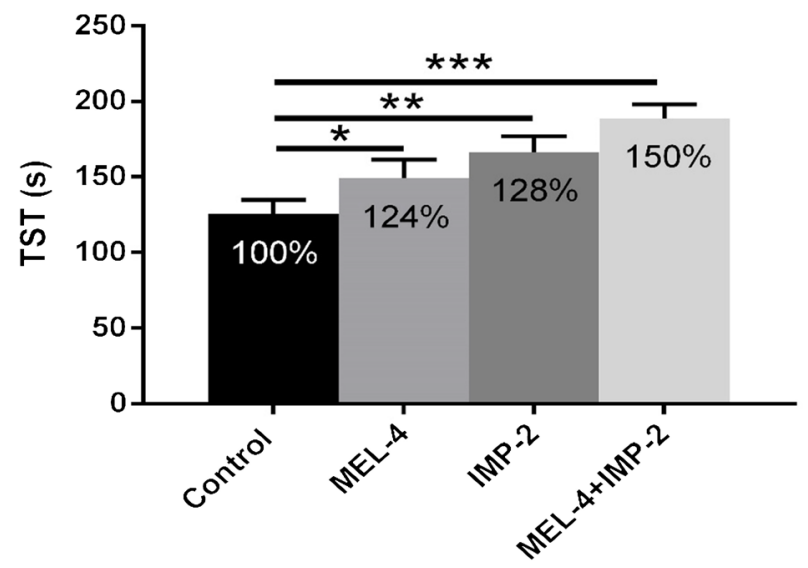

(b)

Figure 3. (a) Immobility time expressed in seconds (s) (TIM); (b) Struggling time expressed in seconds (s) in FST by rats expressed as arbitrary values or as \% of basal level (\% BL), after 4 weeks of treatment with $0.9 \%$ of $\mathrm{NaCl}$ (Control), $4 \mathrm{mg} / \mathrm{kg}$ of $\mathrm{MEL}$ (MEL-4), $2 \mathrm{mg} / \mathrm{kg}$ of IMP (IMP-2) or simultaneously with $4 \mathrm{mg} / \mathrm{kg}$ of MEL and $2 \mathrm{mg} / \mathrm{kg}$ of IMP (MEL-4 + IMP-2). The results are represented as mean \pm SEM. The significance level is $0.05 .{ }^{*} \mathrm{p}<0.05,{ }^{* *} \mathrm{p}<0.01,{ }^{* * *} \mathrm{p}<0.001$. 
statistically lower when compared to that of MEL treated group [(MEL-4/IMP-2 ( $\mathrm{p}$ $<0.001)$, MEL-4/MEL4 + IMP-2 ( $<<0.001)$ ]. In contrast, no significant difference was observed between IMP and (MEL + IMP) groups [(IMP-2/MEL4 + IMP-2 $(\mathrm{p}>0.05)]$.

\section{- Effect on struggling time (TST) (Figure 3(b)):}

Like for the TIM, IMP, MEL and the two drugs combined increase significantly TDT parameter [(control/MEL-4: $\mathrm{p}<0.05)$; (control/IMP-2: $\mathrm{p}<0.01$ ); (control/MEL-4 + IMP-2: $\mathrm{p}<0.001)$ ]. MEL, IMP and two associated molecules induced respectively an augmentation of $24 \%(\mathrm{p}<0.05), 28 \%(\mathrm{p}<0.01)$ and $50 \%$ $(\mathrm{p}<0.001)$ with comparison to control.

Even if there is no real statistical difference between the effects of the two drugs separately administered and those of the two drugs associated [(MEL-4/MEL-4 + IMP-2: $\mathrm{p}>0.05$ ); (IMP-2/MEL-4 + IMP-2: $\mathrm{p}>0.05$ )] showed in the figure, the trend towards meaning is clear and obvious. In contrast, the difference between the groups treated with MEL or IMP was not statistically significant [(MEL-4/IMP-2: $\mathrm{p}>0.05)]$.

\section{Discussion}

The present study aimed to investigate the interaction between MEL and IMP a tricyclic antidepressant. This has therefore allowed identifying a possible interaction of the pineal hormone with monoaminergic systems.

We showed in this study that chronic injection of MEL induced an anxiolytic effect in both OFT and EPM, since the animals of control group are less mobile in the environment of both anxiety paradigms. In FST rats treated with MEL show a significant reduction of TIM and increase of TDT, and therefore show significantly lower levels of depression with comparison to control animals. These results confirm our previous observations showing that chronic administration of MEL produced anxiolytic and antidepressant activities [13] [14]. These results were also consistent with reports of majority studies which reported a significant reduction in anxiety behavior in animals treated with pharmacological doses of MEL, whatever the experimental conditions used, anxiogenic situations and animal species [7] [15] and are a good agreement with data reported in previous observations showing that chronic administration of MEL produced a real antidepressant-like effect [16].

In this study, we have also shown that a very low dose of IMP $(2 \mathrm{mg} / \mathrm{kg})$ is capable of inducing strong anxiolytic and antidepressant activities when injected daily for several weeks. To our knowledge, this study is the first one to show an effect of low dose in comparison with other studies [17]. Recently, Detanico et al. (2009), using chronic administration of exogenous MEL ( 1 and $10 \mathrm{mg} / \mathrm{kg}$ ) and IMP $(20 \mathrm{mg} / \mathrm{kg})$, showed that changes in coat state, grooming behavior and corticosterone levels induced by unpredictable chronic mild stress are suppressed by MEL and IMP. Our results associated with these data show that the two molecules have strong behavioral effects and our experimental conditions 
are more sensitive since the effects of both drugs are detectable at low concentrations.

In addition to the independent effects of MEL and IMP, we show in this study that the pineal hormone improves or enhances anxiolytic and antidepressant effects induced by IMP; behavioral effects induced by the co-administration of MEL and IMP being in fact significantly higher than those obtained with the two molecules injected separately. Improving of IMP action by MEL is observed in all behavioral indexes measured in OFT (TCA, NRC), EPM (TOA, EOA) and FST (TIM and TST) corroborating the existence of a real interaction between the two molecules. This interaction between MEL and IMP antidepressant activities was recently reported in mice [17]. In this study, co-administration of sub-effective doses of IMP (20 mg/kg) and MEL (5 mg/kg) does not affect the response compared to the effects of each drug alone. Instead, the co-administration of effective doses (10 mg/kg of MEL and $40 \mathrm{mg} / \mathrm{kg}$ of IMP) had an additive effect. It appears from these results that there is real interaction between the two drugs. Our results have some advantages since the two substances are efficient at low doses and the effect of IMP is improved by an addition of MEL. Although the IMP mechanism of action has not been completely resolved, it is certain that it interferes with the reuptake of monoamines and increasing concentrations of $\mathrm{NE}$ and 5-HT or DA in the synaptic cleft. Indeed, IMP affects many neurotransmitter systems known to be involved in the etiology of depression and anxiety by causing a strong modification in the turnover of 5-HT, NE, DA, Ach, histamine, Opioid and BDNF.

IMP is known to induce a very strong inhibition of the reuptake of 5-HT. Of a group of TCA, this drug has the second highest affinity for the carrier of the 5-HT behind clomipramine. This causes a very strong and proportional effect on blocking the reuptake of 5-HT [9]. In favor of this hypothesis, studies based on the combination of the MEL and agonists or antagonists of 5-HT receptors, that report their involvement in the regulation of affective disorder [18] [19].

As mentioned above, the diversity of IMP targets and mechanisms of action complicates the understanding of the interaction between MEL and IMP. It is possible that this interaction interested modulating 5-HT neurotransmission since the inhibitory effect of MEL on the TIM in the FST was abolished by the simultaneous injection of luzindole which is non-selective antagonist of MEL [20]. In the same study, it was reported that the reduction of TIM induced by MEL is entirely suppressed by intra-amygdala administration of small amounts of 5-HT or by 1-(2,5-dimethoxy-4-iodophenyl)-2-aminopropane a 5-HT2A/5-HT2C receptor agonist [20]. In humans, it has also been shown that MEL and buspirone exert a synergistic effect in the treatment of acute major depression, while MEL or buspirone remained without effects [21]. Buspirone is a non-benzodiazepine anxiolytic effects with partial agonists 5-HT-ergic 5HT1A, DA-ergic antagonists D2 and central $\alpha 2$-adrenergic blockers. These results may suggest that the effects of the MEL on the emotional behavior of rats in the FST paradigm could be due to an interaction of the hormone with central 5-HT neurotransmission [18]. The 
site of action of MEL allows for selective lengthening struggling behavior in the FST, since agents that interact differently with the NA-ergic and 5-HT-ergic systems exert different effects on the struggling duration. Indeed, it has been shown that MEL would act as an antagonist of 5-HT2A receptors [18]. In addition, the reduction of the TIM in the FST is directly related to a reduction in activity of 5-HT2A receptors, and it was suggested that the observed antidepressant effects in the FST are regulated by 5-HT2A receptors [22]. In addition, it was shown that MEL may regulate the spontaneous efflux and evoked secretion of 5-HT2A receptors in the hippocampus, a major target of 5-HT-ergic antidepressants [23]. The involvement of 5-HT2 receptors is also supported by the anxiolytic and antidepressant activities of agomelatine which is a structural analogue of MEL and antagonist of 5-HT2 receptors [19].

Agomelatine is both an agonist of the MT1 and MT2 receptors and an antagonist of 5-HT 2C receptor, but it does not appear to act via the 5-HT1A receptors as most 5-HT-ergic drugs [19]. Inhibition of 5-HT 2C receptor stimulates NA-ergic pathways and DA-ergic in some brain areas and many studies suggest that antagonists of 5-HT2C receptors could be antidepressants [24] [25]. Agomelatine thus exert an antidepressant effect by its combined effect on MEL and 5-HT receptors [26] [27] [28]. In another study in rats, combining the administration of MEL, measure of neuronal activity in the dorsal raphe, main source of brain 5-HT and TIM in the FST, Domínguez-López et al. (2012) [29] showed that the number of 5-HT neurons spontaneously active and their discharge frequency were both significantly lower under the effect of the intraventricular administration of MEL, while pinealectomy reverse the MEL effect. This inhibitory effect of MEL was completely blocked by the luzindole, antagonist MT1/MT2 receptor, but not by idazoxan, $\alpha 2$-adrenergic antagonist receptors. Simultaneously, the MEL increases the TIM and swimming behavior decrease.

Indeed, in its mechanism of action, IMP affects many neurotransmitter systems known to be involved in the etiology of depression and anxiety by causing:

- Inhibition of the reuptake of NE. The continual conversion of IMP to its metabolite desipramine, which has extremely strong and relatively selective noradrenergic effects allows to moderate the effect of IMP on the reuptake of 5-HT. This mixture of IMP and desipramine provides a strong and simultaneous action on the inhibition of the reuptake of 5-HT and NA [9].

- Reuptake and release of DA at the D1 and D2 receptors. Although this effect is weaker than the main effects of IMP on NA, 5-HT and Ach, it is no less important and is partially responsible for the therapeutic benefits of treatment with IMP. Improving brain DA-ergic activity is involved in the ability of the IMP to stimulate motor activity.

- Inhibition of cholinergic activity: IMP is an anticholinergic that acts by antagonizing the M2 muscarinic receptors. Blocking of these receptors is known to cause euphoria, potentially contributing to the effects of IMP on mood.

- Inhibition of $\alpha 2$-adrenergic receptors causing a general decrease in CNS ac- 
tivity and contributes to the anxiolytic properties of the IMP.

- Antagonizing histamine receptors H1. This contributes to the acute sedative effect that the IMP cause in most of patients. Antihistamines and calming actions of IMP take effect immediately, why low doses of IMP are sometimes used as a sleeping aid.

- Increased of BDNF levels part of the neurotrophic family and which are nerve growth factors. Studies suggest that depressed patients have reduced BDNF levels associated with a low hippocampal neurogenesis which is improved by IMP administration.

Increased expression of opioid $\mu$ receptors. It has been shown that IMP stimulates the expression of opioid $\mu$ receptors in rat forebrain and opioids are involved in improving of mood [30].

The synergistic effect between MEL and IMP can also be explained by the modulation of central DA-ergic activity. Thus, it was shown that MEL has anti-DA-ergic activity by inhibiting the release of DA in specific areas of the CNS of mammals, including the hypothalamus, hippocampus and striatum [31]. This suggests that the MEL interfere with certain disorders involving DA. In this sense, it has been shown that depression induced behavior in mice is prevented by the MEL. The MEL antidepressant effect itself is prevented by a pretreatment of mice with haloperidol (non-selective antagonist of DA receptors), the SCH-23390 (selective D1 receptor antagonist) and sulpiride (selective D2 receptors antagonist) [32]. This study clearly indicates that the MEL antidepressant effect may be mediated by interaction with the DA-ergic system through activation of D1 and/or D2 receptors [32]. Paradoxically, MEL reinforces the antidepressant effect of reserpine by further reducing the TIM in the FST in mice and rats [8]. However, it is known that reserpine is an inhibitor of neurotransmission of 5-HT, NA and DA, until depletion of monoamines stocks and this inhibition is involved in depression in the human. After the text edit has been completed, the paper is ready for the template. Duplicate the template file by using the Save As command, and use the naming convention prescribed by your journal for the name of your paper. In this newly created file, highlight all of the contents and import your prepared text file. You are now ready to style your paper.

\section{Conclusion}

To summarize, our data from numerous research show an implication of MEL and interaction between MEL and IMP in modulation of anxiety-like and depression-like behavior in rats but do not demonstrate any mechanism of action. All these data suggest that alteration of the sensitivity of certain monoaminergic receptors by MEL could be responsible for the interaction between MEL and IMP and, thence, to explain the mechanism action of MEL in this interaction. Additional understanding of melatonin association with other neurotransmitters may contribute to demonstrate a more important contribution of pineal hormone to affective disorder. 


\section{Conflicts of Interest}

The authors declare no conflicts of interest regarding the publication of this paper.

\section{References}

[1] Boulenger, J.P., Fournier, M., Rosales, D. and Lavallee, Y.J. (1997) Mixed Anxiety and Depression: From Theory to Practice. Journal of Clinical Psychiatry, 58, 27-34. https://doi.org/10.4088/JCP.v58n0107

[2] Paul, S.M., Rehavi, M., Skolnick, P. and Al, E. (1981) Depressed Patients Have Decreased Binding of Titiated Imipramine to Platelet Serotonin “Transporter". Archives of General Psychiatry, 38, 1315-1317. https://doi.org/10.1001/archpsyc.1981.01780370017001

[3] McIntyre, I.M., Judd, F.K., Marriott, P.M., Burrows, G.D. and Norman, T.R. (1989) Plasma Melatonin Levels in Affective States. International Journal of Clinical Pharmacology Research, 9, 159-164. http://europepmc.org/abstract/MED/2714920

[4] Brown, R., Kocsis, J.H., Caroff, S., Amsterdam, J., Winokur, A., Stokes, P.E. and Frazer, A. (1985) Differences in Nocturnal Melatonin Secretion between Melancholic Depressed Patients and Control Subjects. American Journal of Psychiatry, 142, 811-816. https://doi.org/10.1176/ajp.142.7.811

[5] Bourin, M., Mocaër, E. and Porsolt, R. (2004) Antidepressant-Like Activity of S 20098 (Agomelatine) in the Forced Swimming Test in Rodents: Involvement of Melatonin and Serotonin Receptors. Journal of Psychiatry \& Neuroscience, 29, 126-133. http://www.ncbi.nlm.nih.gov/pmc/articles/PMC383344

[6] Wong, P.T.-H. and Ong, Y.P. (2001) Acute Antidepressant-Like and Antianxiety-Like Effects of Tryptophan in Mice. Pharmacology, 62, 151-156.

https://doi.org/10.1159/000056088 https://www.karger.com/DOI/10.1159/000056088

[7] Sokolovic, D., Djordjevic, B., Kocic, G., Babovic, P., Ristic, G., Stanojkovic, Z., Sokolovic, D.M., Veljkovic, A., Jankovic, A. and Radovanovic, Z. (2012) The Effect of Melatonin on Body Mass and Behaviour of Rats during an Exposure to Microwave Radiation from Mobile Phone. Bratislavské lekárske listy, 113, 265-269.

http://europepmc.org/abstract/MED/22616582

https://doi.org/10.4149/BLL_2012_062

[8] Shaji, A.V. and Kulkarni, S.K. (1998) Central Nervous System Depressant Activities of Melatonin in Rats and Mice. Indian Journal of Experimental Biology, 36, 257-263.

[9] Richelson, E. and Pfenning, M. (1984) Blockade by Antidepressants and Related Compounds of Biogenic Amine Uptake into Rat Brain Synaptosomes: Most Antidepressants Selectively Block Norepinephrine Uptake. European Journal of Pharmacology, 104, 277-286. https://doi.org/10.1016/0014-2999(84)90403-5

[10] Gentsch, C., Lichtsteiner, M. and Feer, H. (1987) Open Field and Elevated Plus-Maze: A Behavioural Comparison between Spontaneously Hypertensive (SHR) and Wistar-Kyoto (WKY) Rats and the Effects of Chlordiazepoxide. Behavioural Brain Research, 25, 101-107. https://doi.org/10.1016/0166-4328(87)90003-9

[11] Naranjo-Rodriguez, E.B., Osornio, A.O., Hernandez-Avitia, E., Mendoza-Fernandez, V. and Escobar, A. (2000) Anxiolytic-Like Actions of Melatonin, 5-Metoxytryptophol, 5-Hydroxytryptophol and Benzodiazepines on a Conflict Procedure. Progress in Neuro-Psychopharmacology \& Biological Psychiatry, 24, 117-129. 
https://doi.org/10.1016/S0278-5846(99)00075-5

[12] Porsolt, R.D., Anton, G., Blavet, N. and Jalfre, M. (1978) Behavioural Despair in Rats: A New Model Sensitive to Antidepressant Treatments, European Journal of Pharmacology, 47, 379-391. https://doi.org/10.1016/0014-2999(78)90118-8

[13] El Mrabet, F., Ouakki, S., Mesfioui, A., El Hessni, A. and Ouichou, A. (2012) Pinealectomy and Exogenous Melatonin Regulate Anxiety-Like and Depressive-Like Behaviors in Male and Female Wistar Rats. Neuroscience and Medicine, 3, 394-403. https://doi.org/10.4236/nm.2012.34049

[14] Ouakki, S., El Mrabet, F., Mesfioui, A., El Hessni, A. and Ouichou, A. (2013) Interaction Evidence of Melatonin and Hydroxyzine on the Level of Anxiety-Like and Depression-Like in Male and Female Rats. Science Library, 5, 2111-4706.

[15] Karakaş, A., Coşkun, H., Kaya, A., Kücük, A. and Gündüz, B. (2011) The Effects of the Intraamygdalar Melatonin Injections on the Anxiety like Behavior and the Spatial Memory Performance in Male Wistar Rats. Behavioural Brain Research, 222, 141-150. https://doi.org/10.1016/j.bbr.2011.03.029

[16] Detanico, B.C., Piato, Â.L., Freitas, J.J., Lhullier, F.L., Hidalgo, M.P., Caumo, W. and Elisabetsky, E. (2009) Antidepressant-Like Effects of Melatonin in the Mouse Chronic Mild Stress Model. European Journal of Pharmacology, 607, 121-125. https://doi.org/10.1016/j.ejphar.2009.02.037

[17] Ergun, Y., Orhan, F.O. and Karaaslan, M.F. (2008) Combination Therapy of Imipramine and Melatonin: Additive Antidepressant Effect in Mouse Forced Swimming Test. European Journal of Pharmacology, 591, 159-163.

https://doi.org/10.1016/j.ejphar.2008.06.070

[18] Gorzalka, B.B., Brotto, L.A. and Hong, J.J. (1999) Corticosterone Regulation of 5-HT2A Receptor-Mediated Behaviors: Attenuation by Melatonin. Physiology \& Behavior, 67, 439-442. https://doi.org/10.1016/S0031-9384(99)00096-7

[19] Hanoun, N., Mocaer, E., Boyer, P.-A., Hamon, M. and Lanfumey, L. (2004) Differential Effects of the Novel Antidepressant Agomelatine (S 20098) versus Fluoxetine on 5-HT1A Receptors in the Rat Brain. Neuropharmacology, 47, 515-526. https://doi.org/10.1016/j.neuropharm.2004.06.003

[20] Micale, V., Arezzi, A., Rampello, L. and Drago, F. (2004) Melatonin Affects the Immobility Time of Rats in the Forced Swim Test: The Role of Serotonin Neurotransmission. European Neuropsychopharmacology, 16, 538-545. https://doi.org/10.1016/j.euroneuro.2006.01.005

[21] Fava, M., Targum, S.D., Nierenberg, A.A., Bleicher, L.S., Carter, T.A., Wedel, P.C., Hen, R., Gage, F.H. and Barlow, C. (2012) An Exploratory Study of Combination Buspirone and Melatonin SR in Major Depressive Disorder (MDD): A Possible Role for Neurogenesis in Drug Discovery. Journal of Psychiatric Research, 46, 1553-1563. https://doi.org/10.1016/j.jpsychires.2012.08.013

[22] Sibille, E., Sarnyai, Z., Benjamin, D., Gal, J., Baker, H. and Toth, M. (1997) Antisense Inhibition of 5-Hydroxytryptamine 2a Receptor Induces an Antidepressant-Like Effect in Mice. Molecular Pharmacology, 52, 1056-1063.

https://doi.org/10.1124/mol.52.6.1056

[23] Monnet, F.P. (2002) Melatonin Modulates [3H] Serotonin Release in the Rat Hippocampus: Effects of Circadian Rhythm. Journal of Neuroendocrinology, 14, 194-199. https://doi.org/10.1046/j.0007-1331.2001.00761.x

[24] Millan, M.J., Gobert, A., Lejeune, F., Dekeyne, A., Newman-Tancredi, A., Pasteau, V., Rivet, J.-M. and Cussac, D. (2003) The Novel Melatonin Agonist Agomelatine (S20098) Is an Antagonist at 5-Hydroxytryptamine 2c Receptors, Blockade of 
Which Enhances the Activity of Frontocortical Dopaminergic and Adrenergic Pathways. Journal of Pharmacology and Experimental Therapeutics, 306, 954-964. https://doi.org/10.1124/jpet.103.051797

[25] Wood, M.D., Thomas, D.R. and Watson, J.M. (2002) Therapeutic Potential of Serotonin Antagonists in Depressive Disorders. Expert Opinion on Investigational Drugs, 11, 457-467. https://doi.org/10.1517/13543784.11.4.457

[26] Pjrek, E., Winkler, D., Konstantinidis, A., Willeit, M., Praschak-Rieder, N. and Kasper, S. (2007) Agomelatine in the Treatment of Seasonal Affective Disorder. Psychopharmacology, 190, 575-579. https://doi.org/10.1007/s00213-006-0645-3

[27] Rouillon, F. (2006) Efficacy and Tolerance Profile of Agomelatine and Practical Use in Depressed Patients. International Clinical Psychopharmacology, 21, S31-S35. https://doi.org/10.1097/01.yic.0000195659.99148.09

[28] Montgomery, S.A. (2006) Major Depressive Disorders: Clinical Efficacy and Tolerability of Agomelatine, a New Melatonergic Agonist. European Neuropsychophar macology, 16, S633-S638. https://doi.org/10.1016/S0924-977X(06)70009-8

[29] Domínguez-López, S., Mahar, I., Bambico, F.R., Labonté, B., Ochoa-Sánchez, R., Leyton, M. and Gobbi, G. (2012) Short-Term Effects of Melatonin and Pinealectomy on Serotonergic Neuronal Activity across the Light-Dark Cycle. Journal of Psychopharmacology, 26, 830-844. https://doi.org/10.1177/0269881111408460

[30] de Gandarias, J.M., Echevarria, E., Acebes, I., Silio, M. and Casis, L. (1998) Effects of Imipramine Administration on Mu-Opioid Receptor Immunostaining in the Rat Forebrain. Arzneimittel Forschung, 48, 717-719. http://europepmc.org/abstract/MED/9706370

[31] Zisapel, N. (2001) Melatonin-Dopamine Interactions: From Basic Neurochemistry to a Clinical Setting. Cellular and Molecular Neurobiology, 21, 605-616. https://doi.org/10.1023/A:1015187601628

[32] Binfaré, R.W., Mantovani, M., Budni, J., Santos, A.R.S. and Rodrigues, A.L.S. (2010) Involvement of Dopamine Receptors in the Antidepressant-Like Effect of Melatonin in the Tail Suspension Test. European Journal of Pharmacology, 638, 78-83. https://doi.org/10.1016/j.ejphar.2010.04.011 